\title{
Cloning and Characterization of Microsatellite Loci in a Gorgonian Coral, Junceella juncea (Anthozoa; Octocorallia; Ellisellidae) and Its Application in Clonal Genotyping
}

\author{
Shang-Yin Vanson Liu, ${ }^{1}$ Chang-Feng Dai, ${ }^{1}$ Tung-Yung Fan, ${ }^{2}$ Hon-Tsen $\mathbf{Y u}^{3}$ \\ ${ }^{1}$ Institute of Oceanography, National Taiwan University, Taipei, Taiwan, ROC 10617 \\ ${ }^{2}$ National Museum of Marine Biology and Aquarium, Pingtung, Taiwan, ROC 944 \\ ${ }^{3}$ Institute of Zoology and Department of Life Science, National Taiwan University, Taipei, Taiwan, ROC 10617
}

Received: 25 September 2003 / Accepted: 3 February 2004 / Online publication: 11 March 2005

\begin{abstract}
We attempted to isolate microsatellites from a Symbiodinium-free gorgonian octocoral, Junceella juncea, using two methods, partial genomic library screening and enrichment. Among the 3856 clones screened by the partial library method, 10 possibly positive signals were found, and 3 of them could be used to design primers and amplified consistently. In contrast, only one locus isolated by the enrichment method gave reliable amplification and was useful. The results indicate that microsatellites are rare in Junceella juncea, as reported for other cnidarians. Overall, we obtained 4 polymorphic loci to test the feasibility in investigating clonal structure of $J$. juncea. A total of 40 multilocus genotypes were found among 152 colonies, and the number of genotypes (clones) identified at 7 reefs ranged from 2 to 16 . The results of a nonmetric multidimensional scaling analysis indicated the recruitment of I. juncea populations mainly comes from selfretention. These novel microsatellite loci will provide a useful tool to study clonal structure and population genetics for $J$. juncea in the future.
\end{abstract}

Key words: Junceella - microsatellite - clonal structure - coral

\section{Introduction}

Simple sequence repeats, or microsatellites, are tandem repeats of 1 to 6 nucleotides and are dis-

Correspondence to: Hon-Tsen Yu; E-mail: ayu@ntu.edu.tw tributed throughout the eukaryotic and prokaryotic genomes (Ashley and Dow, 1994). Unequal crossing over in meiosis and strand slippage replication are recognized as two major mechanisms for creating polymorphisms of microsatellites (Levinson and Gutman, 1987). Strand-slippage replication appears to be the predominant mode at microsatellites, and this slippage creates a loop that upon DNA repair would either be removed or lead to the elongation of the repeat. The high variances, the ability to distinguish codominant alleles, Mendelian inheritance, and likely neutrality make it useful to study parentage, population genetics, and conservation genetics (Goldstein and Schlötterer, 1999).

In Anthozoa, few microsatellite loci have been reported. One of the reasons is that most coral species contain algal endosymbionts (zooxanthellae), the DNA of which is easily mixed with coral DNA during conventional DNA extraction procedures. The algal DNA contamination makes it extremely difficult, if not impossible, to clone microsatellites from these corals unless some "decontamination" steps are used (Maier et al., 2001). The algal contamination does not pose a problem for the azooxanthellate coral, such as deep-sea coral Lophelia pertusa (Le Goff and Rogers, 2002), which does not contain endosymbiont algae. Nonetheless, after various approaches to clone microsatellite from corals were attempted by Márquez et al. (2003), these authors concluded that in general microsatellite loci were scarce in coral genomes.

Junceellam juncea Pallas, 1776 is an azooxanthellate whip-like gorgonian coral distributed widely in Indo-Pacific reefs including New Guinea, Kei Island, Aru Island, Flores Sea, Banda Anchorage, Timor, the Philippines, Australia, and Taiwan (Chen and Chang, 1991). Around Taiwan, J. juncea colonies 
often grow on sheltered areas of reef knolls or flat limestone substrates between 15 and $30 \mathrm{~m}$ in depth (Chen and Chang, 1991). J. juncea is gonochoric, and gametogenesis may occur twice a year (T.-Y. Fan, unpublished data). In some locations around Taiwan, they form dense patches, but at other locations they are sparsely scattered. In addition, spontaneously fragmentation (asexual reproduction) takes place frequently. Consequently, it would be interesting to investigate the clonal structure in J. juncea.

By applying multilocus markers of simple repeated sequence in a ribosomal intergenic spacer, Chen et al. (2002) studied clonal structure in a congener, Junceella fragilis. However, we failed to obtain amplification for $J$. juncea with primers developed for $J$. fragilis. Moreover, as interpretation of data from heterospecific markers could be problematic owing to uncertain numbers of multiple copies of ribosomal RNA genes, we decided to obtain novel, preferably single-locus microsatellites from $J$. juncea.

The objective of this study was to report our results to characterize 4 polymorphic microsatellite loci in a gorgonian coral, $J$. juncea. These markers are shown to be effective in discerning clonal genotypes of $J$. juncea and are expected to facilitate future studies of population structure, clonal structure, and recruitment patterns of the species. Moreover, we report the negative side of using the enrichment method (e.g., Hamilton et al., 1999) on cloning microsatellite for $J$. juncea despite the increasingly popular application of this procedure (Zane et al., 2002).

\section{Materials and Methods}

Sampling. Seven sets of samples of Juncella juncea were collected from 3 locations including Xia-shuijui and Nan-wan in southern Taiwan, and Shi-cheng in northern Taiwan (Figure 1). At Nan-wan and Shicheng, where colonies of $J$. juncea were scattered, only 21 and 6 samples were collected, respectively. At Xia-shui-jui, where $J$. juncea colonies were abundant, 3 types of sampling schemes were made. First, 36 colonies were collected along a transect line of $50 \mathrm{~m}$, at a regular distance $(1 \mathrm{~m})$ to avoid collecting clonemates. Second, 3 solitary reefs (A, B, and C), each separated by more than $100 \mathrm{~m}$, were sampled, and all colonies on the $16-\mathrm{m}^{2}$ reefs were marked. A small fragment was broken off from the tip to be used in genotyping. The sample sizes (numbers of colonies) for reefs A, B, and C were 11, 13, and 8, respectively. These 3 solitary reefs were inferred to represent the clonal structure in a $16-\mathrm{m}^{2}$ area. Third, samples were collected from an area of about $100 \mathrm{~m}^{2}$ at $10-\mathrm{m}$ depth, where colonies of $J$. juncea were

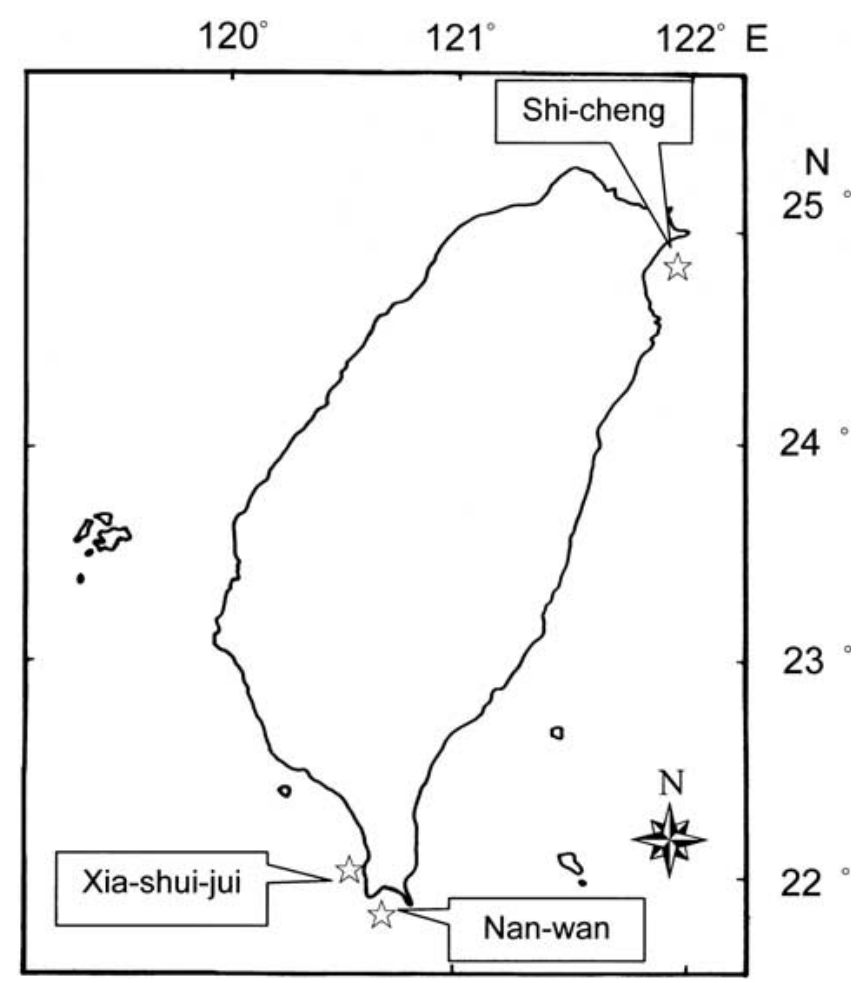

Fig. 1. Map showing collection sites.

previously transplanted from $17-\mathrm{m}$ depth and have been monitored since May 2000. In March 2002, samples of 57 colonies from this area with new recruits were collected.

DNA Extraction. A small fragment $(<2 \mathrm{~g})$ was finely minced with a pair of sterile scissors and placed in a $1.5-\mathrm{ml}$ Eppendorf tube containing $1 \mathrm{ml}$ DNA extraction buffer $(0.4 \mathrm{M} \mathrm{NaCl}, 200 \mathrm{mM}$ EDTA, $\mathrm{pH}$ 8.0). Proteinase K was then added to the samples to a final concentration of $0.1 \mathrm{mg} / \mathrm{ml}$ and incubated at $55^{\circ} \mathrm{C}$ overnight. The samples were then centrifuged at 13,000 rpm for 5 minutes. The supernatant was extracted with equal volumes of phenol and chloroform (1:1) one or two times until the interface became clear, and one time with equal volumes of chloroform. The final supernatant was precipitated with 1.5 volumes of cold $99.5 \%$ ethanol at $-20^{\circ} \mathrm{C}$ for 30 minutes, centrifuged at $13,000 \mathrm{rpm}$ for 20 minutes, and washed with $70 \%$ ethanol. Then the DNA was air-dried, redissolved in $50 \mathrm{ml}$ of $\mathrm{ddH}_{2} \mathrm{O}$, and stored at $-20^{\circ} \mathrm{C}$.

Isolation by Partial Library Method. We followed the method of $\mathrm{Yu}$ et al. (2002) in principle. Genomic DNA $(200 \mu \mathrm{g})$ was digested with Sau AI (New England Biolabs) and fractioned in a 2.5\% Ultra Pure Agarose gel (Gibco, BRL). DNA of size range of 300 to $900 \mathrm{bp}$ was isolated, purified with GFX poly- 
merase chain reactin (PCR) DNA and gel band purification kit (Amershan Pharmacia Biotech) and ligated into plasmids, PUC18/BamHI/BAP (Amersham Pharmacia Biotech) according to the manufacturer's protocols. Ligated plasmids were transformed into competent cells (ECOS-101, Yeastern Biotech). Recombinant clones containing inserts were transferred to Hybond- $\mathrm{N}^{+}$nylon membranes (Amersham Pharmacia Biotech), which were hybridized to a set of oligonucleotide probes, including $(\mathrm{AC})_{10}(\mathrm{AT})_{10}$ $(A A G)_{10}$ and $(A G)_{10}$. Probes were labeled with DIG Oligonuceotide Tailing Kit (Roche). Hybridization was performed at $55^{\circ} \mathrm{C}$ for 24 hours in a standard hybridization buffer, consisting of $5 \times$ SSC, $0.1 \% \mathrm{~N}$ lauroylsarcosine, $0.2 \%$ sodium dodecylsulfate (SDS), and $1 \%$ blocking reagent (Boehringer Mannheim). The membranes were washed twice, each for 5 minutes at $45^{\circ} \mathrm{C}$ with a solution of $2 \times \mathrm{SSC}, 0.1 \%$ SDS, and then twice, each for 15 minutes at $65^{\circ} \mathrm{C}$ with a solution of $0.1 \times$ SSC, $0.1 \%$ SDS.

Chemiluminescent detection was performed with DIG Luminescent Detection Kit for nucleic acid (Roche). Exposure time ranged from 20 to 30 minutes. A total of 9 positive clones were sequenced by DYEamic ET dye terminator kit (MegaBACE) (Amersham Pharmacia Biotech) following the manufacturer's protocols, and analyzed on linear polyacrylamide (LPA) gels with a MegaBACE 500 automated sequencer (Molecular Dynamics). The online program Primer 3.0 available at (http:// www.genome.wi.mit.edu) was used to design primers from flanking regions of the microsatellite loci.

Isolation by Enrichment Method. We followed the procedures of Hamilton et al. (1999) except that we used 3 digestion enzymes instead of 4 (HaeIII, RsaI, and AluI, omitting NheI). This was because that we found the DNA fragments were too small (<300-500 bp) to contain suitable flanking sequences when 4 enzymes were used.

PCR Optimization and Genotyping. PCR conditions were optimized as follow: 5 minutes at $95^{\circ} \mathrm{C}$; 30 cycles of 45 seconds at $94^{\circ} \mathrm{C}, 40$ seconds at annealing temperature $\left(45^{\circ}-60^{\circ} \mathrm{C}\right)$, and 45 seconds at $72^{\circ} \mathrm{C}$ for followed by $72^{\circ} \mathrm{C}$ for 10 minutes. Standard reaction conditions after optimization were $25 \mathrm{ng}$ of each primer, 1.5 to $3 \mathrm{mM} \mathrm{MgCl} 2,10 \times$ PCR buffer, 2.5 nM dNTPs, $1 \mathrm{U}$ of Taq DNA polymerase and 2 to 5 ng DNA in a $25-\mu 1$ reaction volume.

Primers were labeled with fluorescent dye (TAMRA, Fam, and HEX), and PCR products were visualized and sized by automated detection with gel electrophoresis using MegaBACE 500 automated sequencer.

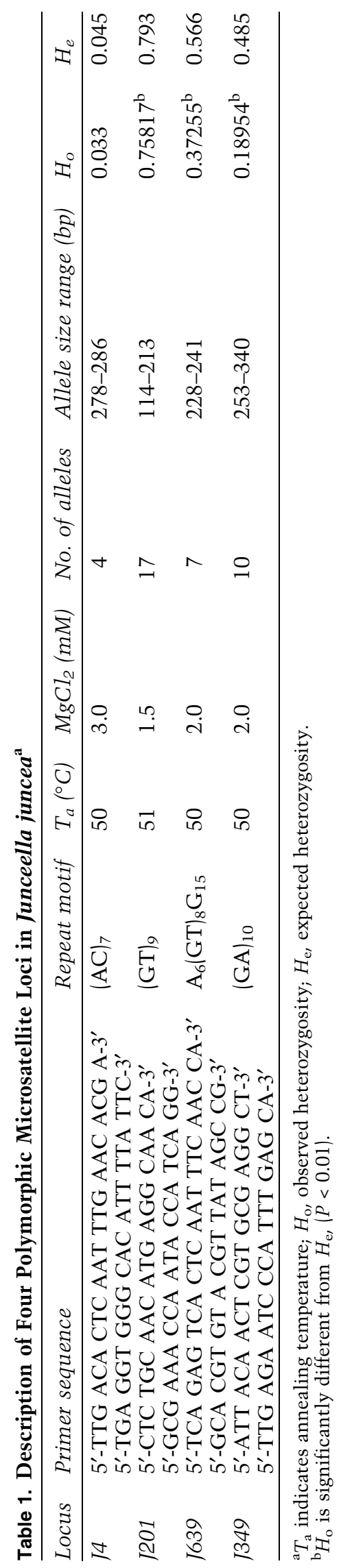


1639

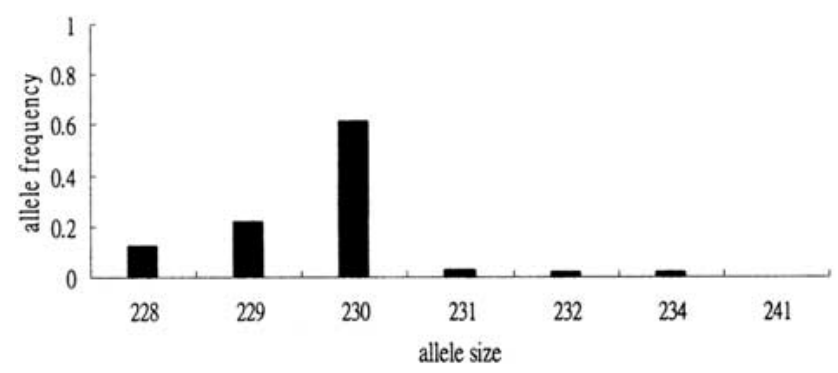

J201

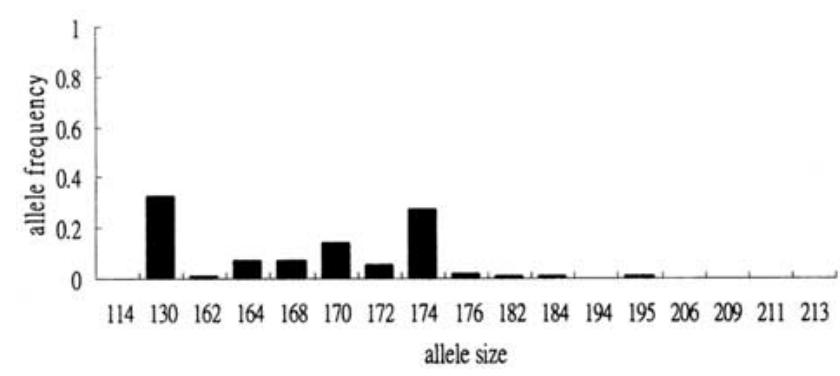

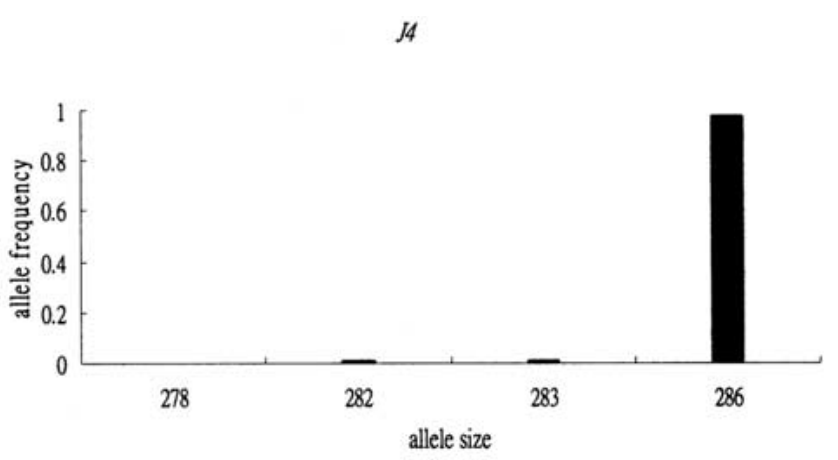

1349

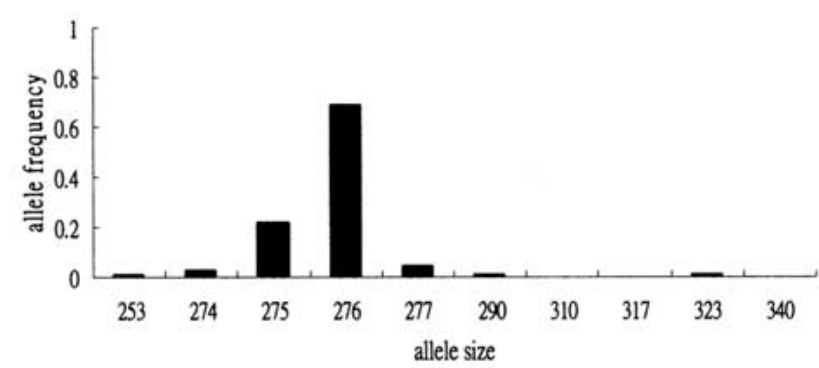

Fig. 2. Frequency distribution of alleles at 4 polymorphic loci for all Junceella juncea samples.

Data Analysis. The genetic diversity of loci was calculated by MSA analysis program (Dieringer and Schlötterer, 2003). The expected heterozygosity $\left(H_{\mathrm{e}}\right)$ and observed heterozygosity $\left(H_{\mathrm{o}}\right)$ were calculated. Hardy-Weinberg expectation for each locus was tested by the Markov-chain method with the program GENEPOP Version 3.3 (Raymond and Rousset, 1995; available at http://wbiomed.curtin.edu.au/genepop), which implements Fisher's exact tests for multiple alleles (Guo and Thompson, 1992).

We employed a multivariate analysis based on the genotypes disclosed at 4 microsatellite loci to visually examine the relationship among clones. Relatedness between clones was measured by the coefficient of Sorensen based on shared alleles (Krebs, 1989), and a nonmetric multidimensional scaling (NMS) analysis was used to illustrate the relationship (Pielou, 1984). Calculation of coefficients and the NMS were executed by PC-ORD (McCune and Mefford, 1999).

\section{Results}

Polymorphic Microsatellite Loci. After enrichment isolation, 235 colonies with an insert larger than 400 bp were sequenced. Among all 235 clones tested, 175 hybridized to corresponding microsatellite sequences, and only 51 sequences had flanking regions longer than $50 \mathrm{bp}$. As a result, 21 pairs of primers were designed for PCR amplifications. Among them, 3 loci worked well and the others failed to have any PCR products even after several optimization attempts. Only 1 of the 3 loci showed polymorphism.

Owing to the poor results of the enrichment method, the partial library method was applied. We constructed 3 libraries from 3 individuals, and a total of 3856 clones were screened, which were hybridized with multiple probes, including $(\mathrm{AC})_{10},(\mathrm{AT})_{10}$, $(A A G)_{10}$ and $(A G)_{10}$. Ten possibly positive signals were found. Nine of 10 contained a repeat motif, and 6 of them could be used to design primers. Three loci could be well amplified and were polymorphic.

Genetic Variation. Level of polymorphism (Table 1) varied among the 4 successfully amplified loci. Numbers of distinct alleles ranged from 4 to 17 per locus. The allele frequencies of 4 polymorphic loci are given in Figure 2; locus 74 was much less variable than the other 3 . The observed and expected heterozygosity ranged from 0.03 to 0.76 and 0.05 to 0.79 , respectively (Table 1). At 3 loci (J201, J349, and J639), the observed genotypes significantly deviated from Hardy-Weinberg expectations $(P<0.01)$ (Table 1$)$. A total of 152 samples of $J$. juncea were analyzed with the 4 polymorphic loci. Among these we identified 40 unique multilocus genotypes (Table 2). 
Table 2. Unique Multilocus Genotypes (clones) Revealed by Four Polymorphic Loci for Junceella juncea Colonies Collected from Xia-shui-jui (Reefs A, B, C, Transplant, Transect), Nan wan, and Shi-cheng

\begin{tabular}{|c|c|c|c|c|c|c|}
\hline \multirow[b]{2}{*}{ Clone } & \multirow[b]{2}{*}{ Sampling date } & \multirow[b]{2}{*}{ Locality } & \multicolumn{4}{|l|}{ Locus } \\
\hline & & & 14 & J201 & $J 639$ & J349 \\
\hline 1 & $4 / 28 / 2002$ & Reef A & $283 / 286$ & $174 / 184$ & $230 / 230$ & $277 / 277$ \\
\hline 2 & $"$ & $"$ & $286 / 286$ & $130 / 164$ & $230 / 230$ & $275 / 275$ \\
\hline 3 & $"$ & $"$ & $283 / 286$ & $182 / 182$ & $229 / 230$ & $277 / 317$ \\
\hline 4 & $”$ & $”$ & $286 / 286$ & $174 / 176$ & $228 / 231$ & $276 / 276$ \\
\hline 5 & $”$ & ” & $282 / 286$ & $174 / 176$ & $228 / 231$ & $276 / 276$ \\
\hline 6 & $"$ & $"$ & $286 / 286$ & $130 / 174$ & $230 / 230$ & $276 / 276$ \\
\hline 7 & 4/29/2002 & Reef B & $286 / 286$ & $168 / 170$ & $229 / 230$ & $276 / 276$ \\
\hline 8 & " & $"$ & $282 / 282$ & $168 / 170$ & $229 / 230$ & $276 / 276$ \\
\hline 9 & $4 / 30 / 2002$ & ReefC & $286 / 286$ & $168 / 174$ & $229 / 230$ & $274 / 276$ \\
\hline 10 & $"$ & $"$ & $286 / 286$ & $174 / 206$ & $229 / 230$ & $253 / 277$ \\
\hline 11 & $10 / 28 / 2002$ & Transplant & $286 / 286$ & $130 / 174$ & $230 / 230$ & $276 / 276$ \\
\hline 12 & $"$ & $"$ & $283 / 286$ & $130 / 174$ & $230 / 230$ & $276 / 276$ \\
\hline 13 & $"$ & 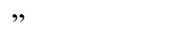 & $278 / 286$ & $130 / 174$ & $230 / 230$ & $276 / 276$ \\
\hline 14 & $9 / 28 / 2002$ & Transect & $286 / 286$ & $170 / 170$ & $229 / 230$ & $275 / 276$ \\
\hline 15 & " & $”$ & $286 / 286$ & $195 / 209$ & $230 / 234$ & $276 / 276$ \\
\hline 16 & $"$ & $"$ & $286 / 286$ & $164 / 172$ & $230 / 230$ & $275 / 275$ \\
\hline 17 & $"$ & $"$ & $286 / 286$ & $164 / 172$ & $229 / 229$ & $276 / 276$ \\
\hline 18 & $"$ & $"$ & $286 / 286$ & $170 / 170$ & $229 / 230$ & $274 / 275$ \\
\hline 19 & $"$ & $"$ & $286 / 286$ & $164 / 172$ & $229 / 229$ & $275 / 275$ \\
\hline 20 & $"$ & $"$ & $286 / 286$ & $164 / 164$ & $230 / 230$ & $275 / 275$ \\
\hline 21 & $"$ & $"$ & $286 / 286$ & $172 / 174$ & $229 / 230$ & $276 / 276$ \\
\hline 22 & $”$ & $"$ & $286 / 286$ & $164 / 172$ & $229 / 229$ & $277 / 340$ \\
\hline 23 & $"$ & $"$ & $286 / 286$ & $168 / 168$ & $230 / 230$ & $276 / 276$ \\
\hline 24 & 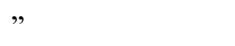 & $"$ & $286 / 286$ & $174 / 211$ & $230 / 230$ & $323 / 323$ \\
\hline 25 & $"$ & $"$ & $286 / 286$ & $182 / 195$ & $230 / 241$ & $277 / 277$ \\
\hline 26 & $"$ & $"$ & $286 / 286$ & $170 / 170$ & $229 / 230$ & $275 / 276$ \\
\hline 27 & $”$ & $"$ & $286 / 286$ & $162 / 162$ & $232 / 232$ & $275 / 275$ \\
\hline 28 & $"$ & $"$ & $286 / 286$ & $170 / 170$ & $229 / 230$ & $274 / 275$ \\
\hline 29 & & $"$ & $286 / 286$ & $184 / 213$ & $229 / 230$ & $253 / 277$ \\
\hline 30 & $1 / 4 / 2003$ & Nan-wan & $286 / 286$ & $130 / 170$ & $230 / 231$ & $275 / 277$ \\
\hline 31 & " & ” & $286 / 286$ & $172 / 195$ & $230 / 231$ & $275 / 277$ \\
\hline 32 & 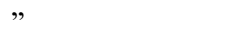 & 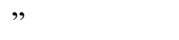 & $286 / 286$ & $114 / 130$ & $228 / 230$ & $275 / 275$ \\
\hline 33 & $"$ & $"$ & $286 / 286$ & $130 / 130$ & $228 / 228$ & $275 / 275$ \\
\hline 34 & $”$ & $"$ & $286 / 286$ & $130 / 174$ & $228 / 228$ & $275 / 277$ \\
\hline 35 & $”$ & 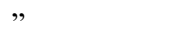 & $286 / 286$ & $172 / 174$ & $230 / 231$ & $290 / 290$ \\
\hline 36 & $”$ & ” & $286 / 286$ & $172 / 174$ & $230 / 231$ & $276 / 276$ \\
\hline 37 & $"$ & $"$ & $286 / 286$ & $130 / 130$ & $230 / 230$ & $275 / 275$ \\
\hline 38 & $11 / 4 / 2002$ & Shi-cheng & $286 / 286$ & $130 / 164$ & $229 / 234$ & $276 / 276$ \\
\hline 39 & " & $"$ & $286 / 286$ & $174 / 174$ & $229 / 232$ & $276 / 276$ \\
\hline 40 & $"$ & $"$ & $286 / 286$ & $184 / 194$ & $229 / 234$ & $277 / 310$ \\
\hline
\end{tabular}

Population Differentiation and Cloning Structure. The MNS analysis visually describes the unique multilocus genotypes (Figure 3). A few points are noteworthy. First, genetic differentiation between northern and southern populations is not obvious because the northern genotypes (SC, genotype 38-40) fall within the realm of the southern populations. Second, the two southern populations (Nan-wan and Xia-shui-jui) contain genetically diverse clones as the genotypes are scattered in the NMS plots. Third, a single reef was represented by a few genotypes (clones), and often these clones were genetically close, for instance, genotypes 1,4 , and 5 on reef A. Fourth, the not only are the transplants represented by just 3 genotypes (genotypes 11-13), but also these genotypes are genetically close. Fifth, within Xia-shui-jui the sampling scheme by transect appears to be the most effective way to assess the genetic diversity in populations of this species.

\section{Discussion}

Two aspects of concern in the isolation of microsatellite from corals are the methodology and the nature of the coral genome. Despite efforts to avoid algal DNA contaminations and to include several isolation approaches, Márquez et al. (2003) reported difficulties in isolating coral microsatellites. They concluded that the genome sizes of corals were smaller than those of typical mammals and birds, 


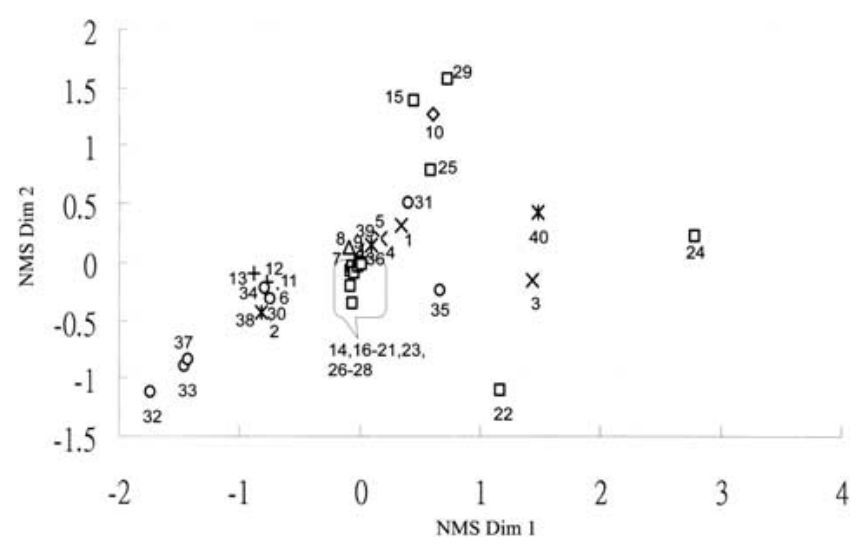

Fig. 3. Nonmetric multidimensional scaling (NMS) analysis of 40 unique genotypes (clones) of Junceella junce. Numbers refer to the genotype numbers listed in Table 3. $A$ indicates reef $A ; B$, reef $B ; C$, reef $C$; TP, transplant; $T S$, transect; NW, Nan-wan; SC, Shi-cheng.

and thereby that coral genomes contain many fewer repetitive elements, including microsatellite loci. While enrichment methods are supposed to offer some advantages while working with genomes containing few microsatellites, our experiences indicate that although the procedure may help to gain a higher proportion of positive clones in the screening, it creates other problems. The enrichment procedures tend to promote in vitro hybridization during PCR, making successful amplification difficult (Koblizkova and Dolezel, 1998). Although a remedy to this complication was proposed (Koblizkova and Dolezel, 1998) by labeling the probes at $3^{\prime}$ end instead of at the usual $5^{\prime}$ end, at least one study did not find the remedy useful (Connors and Cabe, 2003). For our results, among the 21 primer pairs designed by the enrichment method, more than a third (8) of the microsatellites shared partial sequence with another microsatellite, implying the occurrence of in vitro hybridization. Moreover, most primer pairs could not generate any products even after optimization. In the end, only one locus (J4) amplified satisfactorily and was polymorphic. In addition, any enrichment would introduce a bottleneck effect on the micorsatellite loci (Zane et al., 2002).

Although the traditional partial genomic library screening method is time-consuming, it avoids the complication of PCR artifacts (Zane et al., 2002). After the failure of the enrichment method, we applied the traditional partial library method to isolate microsatellites. As a result, we obtained 9 positive clones out of 3856 clones. At any rate, our attempt with screening a partial library of $J$. juncea indicated that this gorgonian coral contains a low abundance of microsatellite loci, in agreement with the conclusion drawn by Márquez et al. (2003) studying stony corals.
Expect for the 14 locus (which could not be tested because there were few heterozygotes in 152 samples), the other 3 loci showed significant deviation from Hardy-Weinberg expectation with heterozygosity deficiency (Table 2). Several factors may lead to the deviation from Hardy-Weinberg expectation in corals, such as life history pattern (prevailing asexual reproduction), Wahlund effect (Hartl and Clark, 1989), and presence of null alleles (Pemberton et al., 1995). Although we cannot rule out the effect of null alleles, it appears that Wahlund effect (mixing of populations) cannot be the cause because the significant deviation remained $(P<0.05)$ when only the population of largest sample size (Xia-shui-jui, $n=125$ ) was tested against Hardy-Weinberg expectation. Therefore, the most likely cause could be asexual reproduction in J. juncea (spontaneous fragmentation is common). Chen et al. (2002) also reported asexual reproduction in another congener, I. fragile. Previous allozyme studies on corals also revealed significant departure from the Hardy-Weinberg expectation with heterozygote deficiency (Stoddart, 1984; Adjeroud and Tsuchiya, 1999|, supposedly indicating that asexual reproduction may be common in these corals.

The results of NMS analysis indicate that the 4 microsatellite loci are useful in discerning coral individuals and clones. Moreover, the genotyping reveals some clones within a reef are closely related to one another. Some previous studies have proved that local retention occurred among brooding corals (Ayre et al., 1997; Ayre and Hughes, 2000). In contrast, Ayre and Hughes (2000) mentioned that some spawning corals also recruited to local populations. Furthermore, local retention was reported among some coral fishes even though these species maintain long dispersal ability (Swearer et al., 1999; Taylor and Hellberg, 2003). Nonetheless, the mechanisms of local retention were still poorly understood. But there are some explanations such as larvae behavior, current pattern and selection may lead to this consequence in several cases (Ayre et al., 1997; Taylor and Hellberg, 2003). The local retention is also witnessed in J. juncea although it is supposed to be an excellent disperser (spawning species). With the microsatellite markers, we will be able to explore further the clonal structure, dispersal, and finescale genetic structure in J. juncea in the future.

\section{Acknowledgments}

Allen Chen offered discussions and comments on an earlier draft. Many people in H.-T. Yu's lab shared their experiences in cloning. We thank them all. This study was supported by the National Science Council of Taiwan (NSC90-2311-B-291-003). 


\section{References}

1. Adjeroud M, Tsuchiya M (1999) Genetic variation and clonal structure in the scleratinian coral Pocilopora damicornis in Ryukyu Archipelago, southern Japan. Mar Biol 134, 753-760

2. Ashley MV, Dow BD (1994) The use of microsatellite analysis in population biology: background, methods and potential application. In: Molecular Ecology and Evolution: Approaches and Applications, Schierwater $\mathrm{B}$, ed. (Birkhasuer, Basel, Switzerland: Birk hauser) pp $185-202$

3. Ayre DJ, Hughes TP, Standish RS (1997) Genetic differentiation, reproductive mode, and gene flow in the brooding coral Pocillopora damicornis among the Great Barrier Reef, Australia. Mar Ecol Prog Ser 159, 175-187

4. Ayre DJ, Hughes TP (2000) Genotypic diversity and gene flow in brooding and spawning corals along the Great Barrier Reef, Australia. Evolution 54, 1590-1605

5. Chen CA, Wei N-W, Dai CR (2002) Genotyping the clonal population structure of a gorgonian coral, Junceella fragilis (Anthozoa: Octocorallia: Ellisellidae) from Lanyu, Taiwan, using simple sequence repeats in ribosomal intergenic spacer. Zool Stud 41, 295-302

6. Chen CC, Chang KH (1991) Gorgonacea (Coelenterata: Anthozoa: Octocorallia) of southern Taiwan. Bull Inst Zool Acad Sin 30, 149-181

7. Connors LM, Cabe PR (2003) Isolation of dinucleotide microsatellite loci from red-backed salamander (Plethodon cinereus). Mol Ecol Notes 3, 131-133

8. Dieringer D, Schlötterer C (2003) Microsatellite analyzer (MSA): a platform independent analysis tool for large microsatellite data sets. Mol Ecol Notes 3, 167-169

9. Goldstein DB, Schlötterer C (1999) Microsatellites Evolution and Applications. (New York, N.Y.: Oxford University Press)

10. Guo SW, Thompson EA (1992) Performing the exact test of Hardy-Weinberg proportion for multiple alleles. Biometrics 48, 361-372

11. Hamilton MB, Pincus EL, DiFiore A, Fleischer R (1999) Universal linker and ligation procedures for construction of genomic DNA libraries enriched for microsatellites. Biotechniques 27, 500-507

12. Hartl DL, Clark AG (1989) Population subdividion and migration. In: Principles of population Genetics. (Sunderland, Mass.: Sinauer Associates Press) pp 281-326

13. Koblizkova A, Dolezel J (1998) Substraction with 3' modified ologonucleotides eliminates amplification artifacts in DNA libraries enriched for microsatellites. Biotechniques 25, 32-38

14. Krebs CJ (1989) Ecological Methodology. (New York, N. Y.: Harper \& Row, Publishers)

15. Le Goff MC, Rogers AD (2002) Characterization of 10 microsatellite loci for the deep-sea coral Lophelia pertusa (Linnaeus 1758). Mol Ecol Notes 2, 164-166

16. Levinson G, Gutman GA (1987) Slipped-strand misrepairing: a major mechanism for DNA sequence evolution. Mol Biol Evol 4, 203-222

17. Maier E, Tollrian R, aand Nürnberger B (2001) Development of species-specific markers in an organism with endosymbionts: microsatellites in the scleractinian coral Seriatopora hystrix. Mol Ecol Notes 1, 157-159

18. Márquez LM, Mackenzie J, Takabayashi M, Smith CR, Chen CA (2003) "Difficulties obtaining microsatellites in acroporid corals". In: Proc. $9^{\text {th }}$ Int. Coral Reef Symp, Bali, Ministry of Environment, Indonesian Institute of Science and International Society for Reef Studies 2: 139-143

19. McCune B, Mefford MJ (1999) Multivariate Analysis of Ecological Data. Version 4.17. (Gleneden Beach, Ore: MjM Software)

20. Pemberton JM, Slate J, Bancroft DR, Barrett JA (1995) Nonamplifying alleles at microsatellite loci: a caution for parentage and population studies. Mol Ecol 4, 249252

21. Pielou EC (1984) The Interpretation of Ecological Data: A Primer on Classification and Ordination. (New York, N.Y.: Wiley)

22. Raymond M, Rousset F (1995) GENEPOP (Version 1.2): population genetics software for exact tests and ecumenicism. J Hered 86, 248-249

23. Stoddart JA (1984) Genetical structure within populations of the coral Pocillopora damicornis. Mar Biol 81, 19-30

24. Swearer SE, Caselle JE, Lea DW, Warner RR (1999) Larval retention and recruitment in an island population of a coral-reef fish. Nature 402, 799-802

25. Taylor MS, Hellberg ME (2003) Genetic evidence for local retention of pelagic larvae in a Caribbean Reef fish. Science 299, 107-109

26. Yu HT, Lee YJ, Huang SW, Chiu TS (2002) Genetic analysis of the populations of Japanese anchovy (Engraulidae: Engraulis japonicus) using microsatellite DNA. Mar Biotechnol 4, 471-479

27. Zane L, Bargelloni L, Patarnello T (2002) Strategies for microsatellite isolation: a review. Mol Ecol 11, 1-16 